\title{
Correction to: Primary headaches during lifespan
}

Andreas Straube ${ }^{1 *}$ and Anna P. Andreou ${ }^{2,3}$

\section{Correction to: J Headache Pain}

$$
\text { https://doi.org/10.1186/s10194-019-0985-0 }
$$

Following publication of the original article [1], we have been notified that one of the author names was incompletely presented. The correction can be seen below.

- Incomplete author name: Last Name: Andreou First Name: Anna

- Complete author name: Last Name: Andreou First Name: Anna P.

Author details

${ }^{1}$ Department of Neurology, University Hospital LMU,

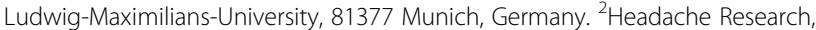
Wolfson CARD, Institute of Psychiatry, Psychology and Neuroscience, King's College London, London, UK. 'The Headache Centre, Guy's and St Thomas', NHS Foundation Trust, London, UK.

Received: 12 June 2019 Accepted: 12 June 2019

Published online: 19 June 2019

\section{Reference}

1. Straube, Andreou (2019) Primary headaches during lifespan. J Headache Pain 20:35. https://doi.org/10.1186/s10194-019-0985-0

\footnotetext{
* Correspondence: andreas.straube@med.uni-muenchen.de

The original article can be found online at https://doi.org/10.1186/s10194019-0985-0

'Department of Neurology, University Hospital LMU,

Ludwig-Maximilians-University, 81377 Munich, Germany

Full list of author information is available at the end of the article
}

(c) The Author(s). 2019 Open Access This article is distributed under the terms of the Creative Commons Attribution 4.0 International License (http://creativecommons.org/licenses/by/4.0/), which permits unrestricted use, distribution, and reproduction in any medium, provided you give appropriate credit to the original author(s) and the source, provide a link to the Creative Commons license, and indicate if changes were made. 